\title{
Perancangan Turbin Tife Pelton Untuk Miniatur Pembangkit Listrik Tenaga Mikro Hidro
}

\author{
Wan Azlan Abdullah \\ Teknik listrik, Universitas Batang hari Jambi \\ Jalan.Slamet Riyadi No.1, RT.09, Sungai Putri, Danau Tlk. Kota Jambi. \\ Correspondence Email: wanazlan024@gmail.com
}

\begin{abstract}
Abstrak. Putaran poros tertinggi terdapat pada penggunaan variasi perbedaan perbandingan: perbedaan perbandingan roda gigi 4 banding 1 yang menghasilkan putaran poros sebesar: 420 dan $400 \mathrm{rpm}$. Sedangkan putaran poros terendah terjadi peda variasi perbedaan perbandingan roda gigi sebesar $280 \mathrm{rpm}$. Debit air yang memutar turbin pelton menghasilkan tegangan keluaran generator sebesar 13.15.18 volt. Daya listrik yang di hasilkan dapat mecharger baterai 12 volt 7,0 Ah dan dapat di bebani lampu led 24 watt. Adapun saran dalam perancangan alat uji turbin pelton skala laboratorium sebagai berikut; jika mau menaikkan kapasitas tegangan yang dihasilkan turbin maka sebagusnya kita harus memperbesar diameter turbin kemudian menambah debit air dan menambah rasio putaran gear supaya daya keluaran generator lebih besar.
\end{abstract}

Kata kunci: turbin; tife pelton, pembangkit listrik; mikro hidro

Abstract. The highest axle rotation is found in the use of variation comparison differences: The 4-to-1 gear comparison difference which results in a round axle of: 420 and $400 \mathrm{rpm}$. While the lowest axle rotation occurs peda different variations of gear comparison of $280 \mathrm{rpm}$. The water discharge that rotates the Pelton turbine generates a generator output voltage of 13.15 .18 volts. Power generated power can be battery Mecharger 12 Volts 7.0 Ah and can be in the lamp burden 24 watts. As for the advice in the design of laboratory scale testing equipment of Pelton scales as follows; If you want to increase the voltage capacity of the resulting turbine so we have to enlarge the diameter of the turbine then increase the water discharge and increase the gear rotation ratio so that the generator output power is greater.

Keywords: turbine; Tife Pelton, power plant; Micro Hydro

\section{PENDAHULUAN}

Air merupakan salah satu sumber bagi kehidupan yang ada di bumi. Baik manusia, hewan dan tumbuhan, semua makhluk hidup memerlukan air untuk dapat mempertahankan kelangsungan hidupnya. Sungai mengalir dari hulu ke hilir bergerak dari tempat yang tinggi ke tempat yang rendah. Di Provinsi Jambi terdapat banyak sekali sungai-sungai besar maupun kecil yang terdapat di berbagai daerah.

Hal ini merupakan peluang yang bagus untuk pengembangan energi listrik di daerah khususnya daerah yang belum terjangkau energi listrik. Pembangkit Listrik Tenaga Mikro Hidro (PLTMH) merupakan alternatif sumber energi listrik bagi masyarakat. PLTMH memberikan banyak keuntungan terutama bagi masyarakat pedalaman di seluruh Provinsi Jambi. Di saat sumber energi lain mulai menipis dan memberikan dampak negatif, maka air menjadi sumber energy yang sangat penting karena dapat dijadikan sumber energi pembangkit listrik yang murah dan tidak menimbulkan polusi.

Pembangkit listrik mikro hidro mengacu pada pembangkit listrik dengan skala di bawah $100 \mathrm{~kW}$. Banyak daerah pedesaan di Kota Jambi yang dekat dengan aliran sungai yang memadai untuk pembangkit listrik. Di harapkan dengan memanfaatkan potensi yang ada di desa - desa tersebut dapat memenuhi kebutuhan energinya sendiri dalam mengantisipasi kenaikan biaya energi atau kesulitan jaringan listrik di Kota Jambi untuk menjangkaunya.

\section{Pembangkit Listrik Tenaga Mikrohidro (PLTMH)}

Pembangkit Listrik Mikrohidro atau dikenal sebagai Pembangkit Listrik Tenaga Mikrohidro (PLTMH) merupakan suatu sistem pembangkit listrik skala kecil yang menggunakan tenaga air sebagai tenaga penggeraknya seperti, saluran irigasi, sungai atau air terjun alam dengan cara memanfaatkan ketinggian dan debit air [2]. PLTMH secara teknis terdiri dari tiga komponen utama yaitu:

1. Air sebagai sumber energi.

2. Turbin (pengubah energi potensial menjadi energi gerak / mekanis).

3. Generator (pengubah energi mekanis menjadi energi listrik).

Prinsip dasar mikrohidro adalah memanfaatkan energi potensial yang dimiliki oleh aliran air pada jarak ketinggian tertentu dari tempat instalasi pembangkit listrik. Sebuah skema mikrohidro membutuhkan dua hal yaitu debit air dan ketinggian jatuh (head) untuk menghasilkan tenaga yang dapat dimanfaatkan. Hal ini adalah sebuah sistem konversi energi dari bentuk ketinggian dan aliran (energi potensial) ke dalam bentuk energi mekanik dan energi listrik [2]. 


\section{Turbin Pelton}

Turbin pelton merupakan pengembangan dari turbin impuls yang ditemukan oleh S.N.Knight tahun 1872 dan N.J. Colena tahun 1873 dengan pasang mangkok-mangkok pada roda turbin. Setelah itu turbin impuls dikembangkan oleh orang amerika Lester G [2]. Pelton (1880) yang melakukan perbaikan dengan penerapan mangkok ganda simetris, punggung membelah membagi jet menjadi dua paruh yang sama yang dibalikan menyamping. Jenis Turbin ini memiliki satu atau beberapa penyemprot air untuk memutar piringan.Tak seperti turbin jenis reaksi, turbin ini tidak memerlukan tabung diffuser. Ketinggian air (head) $=$ 200 s.d 2000 meter. Debit air $=4$ s.d 15 m3/s.

Pancaran air tersebut yang akan menjadi gaya tangensial $\mathrm{F}$ yang bekerja pada mangkok roda jalan. Turbin pelton beroperasi pada tinggi jatuh yang besar. Tinggi air jatuh dihitung mulai dari permukaan atas sampai tengah tengah pancaran air [2]. Bentuk mangkok terbelah menjadi dua bagian yang simetris, dengan maksud adalah agar dapat membalikan pancaran air dengan baik dan membebaskan mangkok dari gaya-gaya samping.

\section{Prinsip dasar}

Turbin pelton merupakan turbin impuls yang prinsip kerjanya mengubah energi potensial air menjadi energi kinetik dalam bentuk pancaran air. Pancaran air yang keluar dari mulut nozel diterima oleh mangkokmangkok pada roda jalan sehingga roda jalan berputar. Dari putaran inilah menghasilkan energi mekanik yang memutar poros generator sehigga menghasilkan energi listrik. Seperti gambar dibawah ini.
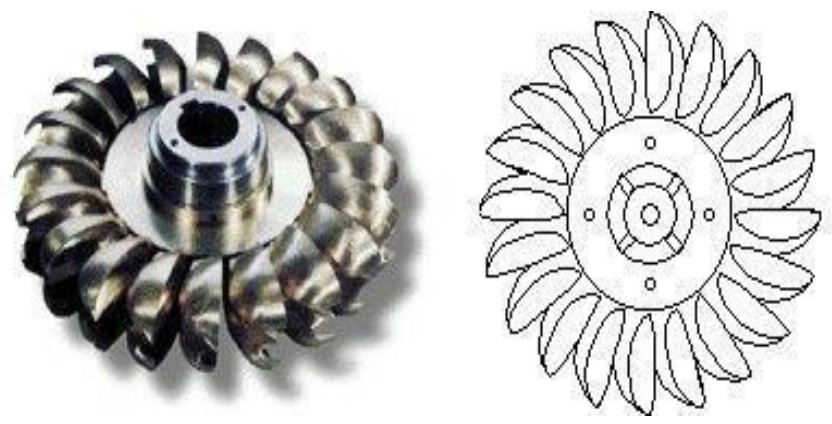

Gambar 1. Turbin pelton

Perancangan turbin pelton dimulai dengan melakukan identifikasi, pertimbangan dan melihat faktor keamanannya untuk dapat menyajikan hasil rancangan dengan baik begitu juga dengan material yang akan digunakan dalam perancangan turbin pelton. Dalam perancangan di butuhkan massa jenis atau density $(\rho)$ untuk dapat menentukan berat jenisnya, massa jenis merupakan massa suatu benda per satuan volume. Sedangkan berat jenis benda adalah berat suatu benda dalam satuan volume, berat mempunyai arah, berat suatu benda dipengaruhi oleh massa benda dan gravitasi [2].

\section{Kecepatan Spesifik Turbin}

Yang dimaksud dengan kecepatan spesifik dari suatu turbin ialah kecepatan putaran runner yang dapat dihasilkan daya effektif 1 BHP untuk setiap tinggi jatuh 1 meter atau dengan rumus dapat ditulis [3].

$$
\begin{aligned}
& \mathrm{n}_{\mathrm{s}}=\mathrm{n} \cdot \mathrm{Ne}^{1 / 2} / \mathrm{H}_{\mathrm{efs}}^{5 / 4} \\
& \text { Diketahui: } \\
& \mathrm{n}_{\mathrm{s}} \quad=\text { kecepatan spesifik turbin } \\
& \mathrm{n} \quad=\text { Kecepatan putaran turbin ...... rpm } \\
& \mathrm{H}_{\mathrm{efs}} \quad=\text { tinggi jatuh effektif ..... m } \\
& \mathrm{N}_{\mathrm{e}} \quad=\text { daya turbin effektif ......HP }
\end{aligned}
$$

\section{Menentukan putaran Turbin}

Putaran spesifik turbin adalah kecepatan turbin model atau bentuk turbin sama, tetapi skalanya berlainan yang bekerja pada satu - satuan head dan satuan debit air yang menghasilkan satu - satuan daya. Penentuan spesifik ini berguna untuk membandingkan semua jenis turbin air pada basis yang sama. Kecepatan spesifik dapat di defenisikan sebagai jumlah putaran permenit pada masa suatu runner tertentu akan berputar sehingga di hasilkan satu - satuan daya untuk satu -satuan head.

Jika kecapatan aliran air dinyatakan dengan $\mathrm{v}$ Maka;

$\mathrm{v}=\sqrt{2 g h}$ dengan

$\mathrm{H}=$ head (tinggi jatuh air )

Substitusi pesamaan putaran spesifik turbin: rpm.

$n_{S}=\left[\frac{n}{H^{1 / 2}}\right]\left[\sqrt{\frac{N}{H^{3 / 2}}}\right]$

$n_{S}=\sqrt[N]{\frac{N}{H^{5 / 4}}} \quad \ldots \ldots . .(\mathrm{rpm})$

Dimana:

$n_{S} \quad=$ putaran spesifik $(\mathrm{rpm})$

$n \quad=$ keceptan putaran turbin (rpm)

$\mathrm{N} \quad=$ daya trubin $(\mathrm{Hp})$

$\mathrm{H} \quad=$ head efektif (m)

Persamaan ini digunakan untuk menghitung kecepatan spesifik trubin. Kecepatan spesifik sangat menentukan tipe yang di rencanakan.

\section{Generator}

Generator dalam bentuknya yang sederhana sebuah generator listrik terdiri atas magnet dan kumparan. Bilamana terdapat gerakan relatif antara kedua komponen maka garis - garis gaya magnet memotong belitan - belitan kumparan dan gaya gerak listrik (ggl) akan dibangkitkan. Sebuah generator listrik atau alternator modern terdiri atas sistem electromagnet dan armatur yang terdiri atas sejumlah kumparan dari konduktor berisolasi yang diletakkan dalam alur (slot) inti besi berlaminasi.seperti gambar dibawah ini. 


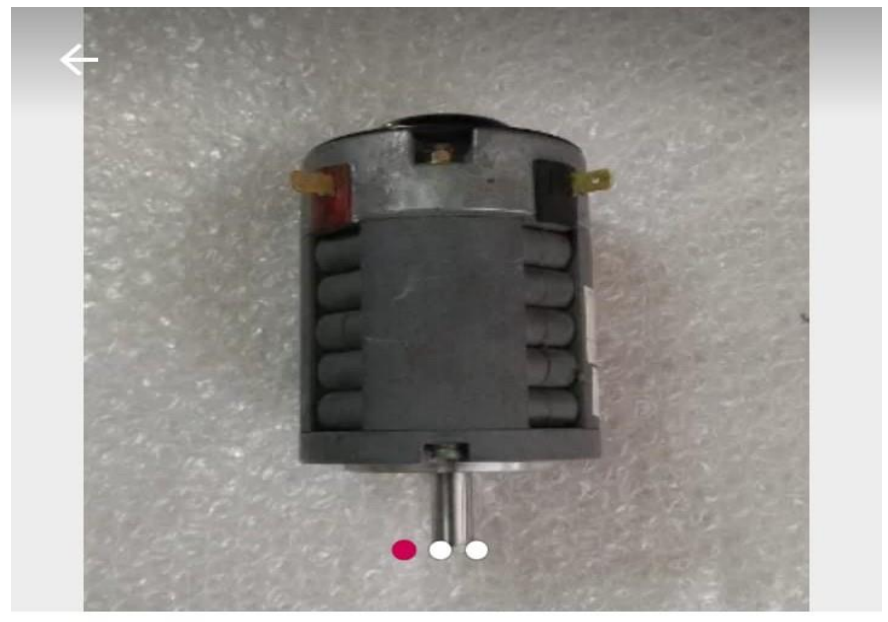

Gambar 2. Generator 270 Watt

Hukum Faraday dapat dinyatakan dengan Tegangan GGL induksi yang dibangkitan bergantung pada:

1. Jumlah dari lilitan dalam kumparan.

2. Kuat medan magnetik, makin kuat medan makin besar tegangan yang diinduksikan.

3. Kecepatan dari generator itu sendiri. Berdasar pada keluarannya, terdapat 2 tipe generator yaitu generator tegangan $\mathrm{AC}$ dan generator tegangan DC.
Generator AC adalah generator yang menghasilkan listrik arus bolak balik. Generator AC termasuk jenis mesin serempak (mesin sikron) dimana frekuensi listrik yang dihasilkan sebanding dengan jumlah kutub dan putaran yang dimilikinya. Generator ini menghasilkan energi listrik bolak - balik (alternating current, AC) [3].

Adapun persamaan atas Daya yang dibangkitkan generator yang diputar oleh Turbin Air adalah:

$P=k . \eta . H . q .[k W]$

Dimana:

$$
\begin{array}{ll}
\mathrm{P} & =\text { daya }[\mathrm{kW}] \\
\mathrm{H} & =\text { tinggi air terjun (meter) } \\
\mathrm{q} & =\text { debit air }\left[\mathrm{m}^{3} / \text { detik }\right] \\
\eta & =\text { efesiensi turbnin bersama generator } \\
\mathrm{k} & =\text { konstanta }
\end{array}
$$

Konstanta (k) dihitung berdasarkan pengertian bahwa 1 daya $\mathrm{kuda}=75 \mathrm{kgm} /$ detik dan 1 daya $\mathrm{kuda}=$ $0,736 \mathrm{~kW}$ sehingga apabila $\mathrm{P}$ ingin dinyatakan dalam $\mathrm{kW}$, sedangkan tinggi air terjun $(\mathrm{H})$ dinyatakan dalam meter dan debit air (q) dalam $\mathrm{m}^{3} /$ detik, maka:

$$
\text { Kontanta } k=\frac{m^{3}}{d e t} \times \frac{1000 \mathrm{~kg}}{m^{3}} \times m \times \frac{1 d k}{75 \frac{\mathrm{kgm}}{\text { det }}} \times 0,736 \frac{\mathrm{kW}}{\mathrm{dk}}=9,813=9,8
$$

\section{METODE}

\section{Tempat dan Waktu}

Perancangan alat di lakukan di bengkel teknik pakultas teknik listrik universitas batanghari jambi.

\section{Diagram Alur}

Penelitian ini dilakukan sesuai dengan diagram alur berikut.

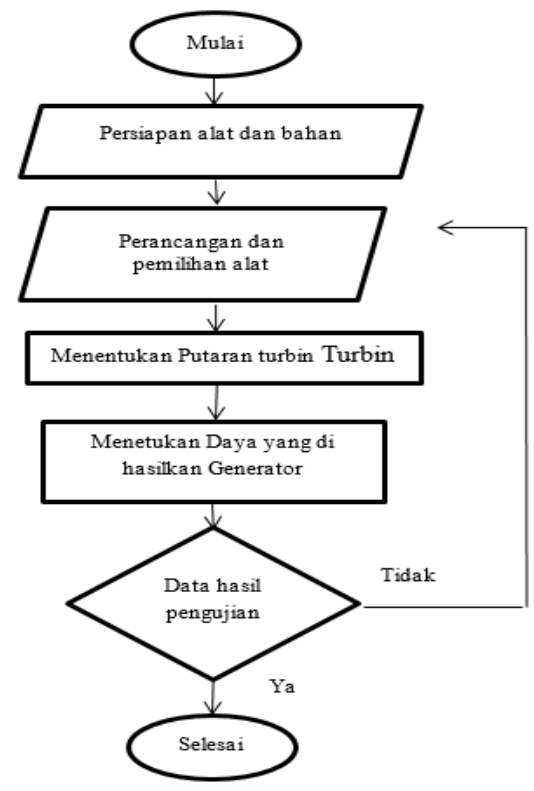

Gambar 3. Diagram Alur

\section{Persiapan Alat Dan Bahan}

Alat

Alat yang digunakan dalam pembuatan turbin pelton adalah;
a. Mesin las.
b. Elektroda.
c. Gerinda.
d. Palu, meteran
e. Sudu.
f. Mistar siku.
g. Busur.
h. Spidol, dan jangka.

\section{Bahan}

Bahan yang digunakan untuk pembuatan turbin pelton adalah
a. Pelat $1.2 \mathrm{~mm}$
b. Sudu 16
c. As motor
d. Klahar motor 5
e. Besi siku

\section{Perancangan dan Pemilihan Alat}

Perancangan dimulai dengan mendata terlebih dahulu alat dan bahan yang sudah ada lalu kemudian dilalukan perhitungan terhadap skala utama turbin pelton Jika sudah berhasil dan sesuai dengan standar yang direncanakan kemudian dilakukan survey ketersediaan 
bahan dipasaran untuk menyesuaikan kebutuhan dari hasil perhitungan yang didapatkan setelah itu dilanjutkan pada pembuatan desain turbin peltonnya namun bila tidak sesuai kembali lagi pada perancangan awal.yang mana percangan dan pemilihan alat.

Peralatan yang digunakan :

1. Trubin pelton yang telah di rangkai

2. 1 buah pompa air

3. Aki untuk membangkitkan listrik yang dapat menghasilkan tengangan dan arus

4. Lampu sebagai beban

5. Baskom

6. Pipa PVC 1 inci

7. Multimeter yang di gunakan untuk mengukur arus dan tengangan yang dihasilkan oleh turbin

8. Alat ukur rpm( tachometer)

9. Kran yang digunakan untuk mengatur debit.

10.Generator

11.Gear

12. As motor

13. Klahar motor

\section{Menentukan Putaran Turbin}

Menentukan putaran turbin bisa di lakukan dengan bermacam variasi sudu biasanya dapat di lakukan dengan 16 sudu trus melaukan pengukuran debit air dengan kapitas bak penampung 140 liter. Kemudian bisa diukur putaran turbin dengan alat ukur tachometer.

\section{Menetukan Daya yang di Hasilkan Generator}

Untuk memilih kemampuan generator dalam menghasilkan energi listrik sesuaikan dengan perhitungan daya 270 watt. dari kecepatan nilai rata turbin kita biasa menentukan daya yang bisa di hasilkan pada generator .dan juga kita harus bisa membuat turbin berputar slalu aktif dan daya yang di hasilkan oleh Generator. Generator juga slalu stabil, kemampuan generator dalam menghasilakn listrik biasanya dinyatakan dalam Volt Ampere (VA) atau dalam kilo Volt Ampere (KVA).

\section{Data Hasil pengujian}

Data hasil pengujian dapat di ambil ketika alat bekerja dengan benar sesuai dengan apa yang telah di rencanakan.

\section{HASIL DAN PEMBAHASAN \\ Rancang Bangun Turbin Pelton}

Rancangan bangun turbin pelton ini saya menggunakan sendok sebagai memutarkan trubin, dan gearbok sebagai transmisi untuk menghubungkan ke generator.

\section{Penentuan debit Air}

Hasil Pengoperasian turbin pelton air waduk di bengkel listrik Universitas Batanghari jambi: waduk penampungan 140 liter. Dengan sudu turbin pelton berjumlah sudu 16. Hasil pengukuruan debit air maksimum yang dilakukan perhitungan sebagai berikut:

$$
\begin{aligned}
\text { Debit } & =\frac{\text { Volume }}{\text { Waktu }} q=\frac{v}{t} \\
\mathrm{v} & =70 \text { liter } \\
\mathrm{t} & =1 \text { menit } \\
\mathrm{v} & =\frac{70}{1000} \mathrm{~m}^{3}=0,07 \mathrm{~m}^{3} \\
\mathrm{t} & =1 \times 60 \text { detik }=60 \text { detik } \\
q & =\frac{v}{t}=\frac{0,07}{60}=0.00116 \mathrm{~m}^{3} / \text { detik }
\end{aligned}
$$

Maka rpm yang di dapatkan dari debit 70 liter dan waktu $0.00116 \mathrm{~m}^{3} /$ detik adalah: $70 \mathrm{rpm}$.

$$
\begin{array}{ll}
\mathrm{v} & =100 \text { liter } \\
\mathrm{t} & =1,5 \text { menit } \\
\mathrm{v} & =\frac{100}{1000} \mathrm{~m}^{3}=0,1 \mathrm{~m}^{3} \\
\mathrm{t} & =1,5 \times 60 \text { detik }=90 \text { detik } \\
\mathrm{q} & =\frac{v}{t}=\frac{0,1}{90}=0,00111 \mathrm{~m}^{3} / \text { detik }
\end{array}
$$

Maka rpm yang di dapatkan dari debit 100 liter dan waktu $0,00111 \mathrm{~m}^{3} /$ detik adalah: $100 \mathrm{rpm}$.

$$
\begin{aligned}
\mathrm{v} & =140 \text { liter } \\
\mathrm{T} & =2 \text { menit } \\
\mathrm{v} & =\frac{140}{1000} \mathrm{~m}^{3}=0,14 \mathrm{~m}^{3} \\
\mathrm{t} & =2 \times 60 \text { detik }=120 \text { detik } \\
\mathrm{q} & =\frac{v}{t}=\frac{0,14}{120}=0,00116 \mathrm{~m}^{3} / \text { detik }
\end{aligned}
$$

Maka rpm yang di dapatkan dari debit 140 liter dan waktu 0,00116 $\mathrm{m}^{3} /$ detik adalah: $105 \mathrm{rpm}$.

\section{Menentukan daya keluaran generator}

Untuk mendapatkan daya teoritis pembangkit listrik mikrohidro menggunakan persamaan sebagai berikut:

$\mathrm{p} \quad=\mathrm{H} \cdot \mathrm{q} \cdot \mu \cdot \mathrm{k}$.

Dari hasil yang pengukuran yang di dapat:

$$
\begin{aligned}
\mathrm{q} & =70 \text { liter } / \text { menit } \\
& =0.00116 \mathrm{~m}^{3} / \text { detik } \\
\mathrm{H} & =130 \mathrm{~cm} \\
& =1,3 \mathrm{~m}
\end{aligned}
$$

Maka:

$$
\begin{aligned}
\mathrm{p} & =\mathrm{k} . \mu . \mathrm{H} . \mathrm{q} \\
\mathrm{k} & =9,8 \times 0,95 \times 1,3 \mathrm{~m} \times 0,00116 \mathrm{~m}^{3} / \text { detik } \\
\mathrm{p} & =0,01412 \mathrm{kw} . \\
\mathrm{q} & =100 \mathrm{liter} / \mathrm{menit} \\
& =0,00111 \mathrm{~m}^{3} / \text { detik } \\
\mathrm{H} & =130 \mathrm{~cm} \\
& =1,3 \mathrm{~m}
\end{aligned}
$$


Maka:

$\mathrm{p} \quad=\mathrm{k} . \mu$. H.q

$\mathrm{k}=9,8 \times 0,95 \times 1,3 \mathrm{~m} \times 0,00111 \mathrm{~m}^{3} /$ detik

$\mathrm{p} \quad=0,01343 \mathrm{kw}$.

$\mathrm{q}=140$ liter $/$ menit

$=0,00116 \mathrm{~m}^{3} /$ detik

$\mathrm{H} \quad=130 \mathrm{~cm}$

$=1,3 \mathrm{~m}$

Maka:

$\mathrm{p} \quad=\mathrm{k} . \mu$. H.q.

$\mathrm{k}=9,8 \times 0,95 \times 1,3 \mathrm{~m} \times 0,00116 \mathrm{~m}^{3} /$ detik

$\mathrm{p} \quad=0,01403 \mathrm{kw}$.

\section{Pengujian Putaran dan Tegangan}
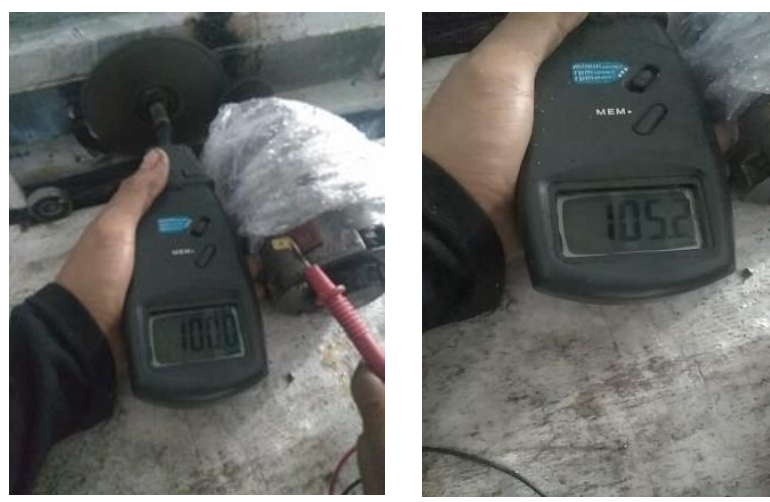

Gambar 4. Hasil pengukuran putaran.

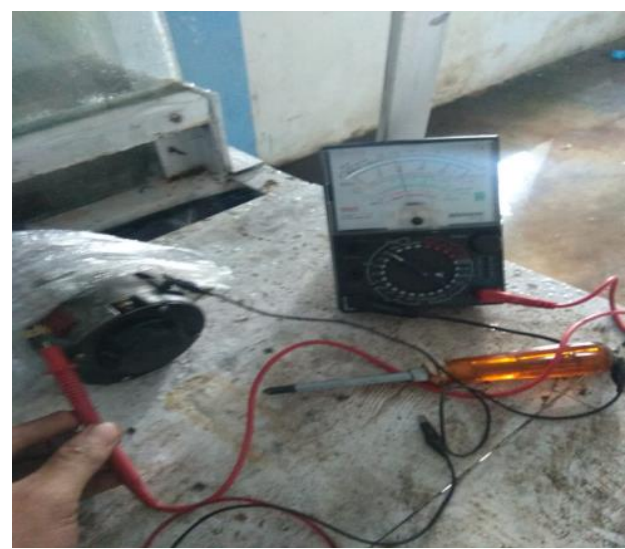

Gambar 5. Daya hasil keluaran generator

Grafik analisa dari rpm terhadap tegangan keluaran generator.

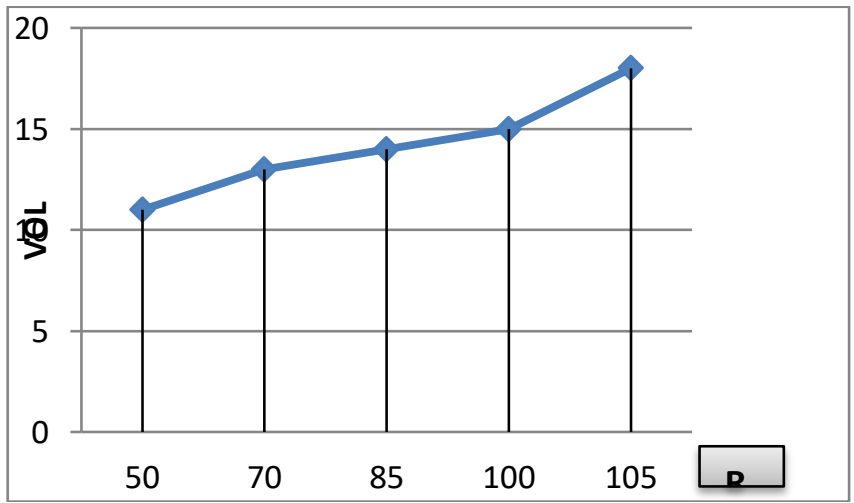

\section{SIMPULAN}

Dapat diperoleh kesimpulan sebagai berikut:

1. Putaran poros tertinggi terdapat pada penggunaan variasi perbedaan perbandingan: perbedaan perbandingan roda gigi 4 banding 1 yang menghasilkan putaran poros sebesar: 420 dan 400 rpm. Sedangkan putaran poros terendah terjadi peda variasi perbedaan perbandingan roda gigi sebesar 280 rpm.

2. Debit air yang memutar turbin pelton menghasilkan tegangan keluaran generator sebesar 13.15 .18 volt.

3. Daya listrik yang di hasilkan dapat mecharger baterai 12 volt 7,0 Ah dan dapat di bebani lampu led 24 watt.

\section{DAFTAR PUSTAKA}

[1] Gorlov, A.M.1998. "Development Of The Helical Reaction Hydraulic Turbin. PIMIME Department Northeastern University Boston,

[2] Gorlov, A.M. 2010. "Helical Turbin and Fish Safety. Mechanical Engineering Department Northeastern University, Boston,

[3] Priatama, I. 2015." Kajian Eksperimental Pengaruh Berat Roda Gila (flywheel) Terhadap Unjuk Kerja Turbin Pelton Untuk Pembangkit Listrik Tenaga Mikro Hidro (PLTMH). "Sekripsi Jurusan Teknik Mesin Universitas Lampung. Bandar lampung

[4] Rapa'i, A. 2014. "Kajian Eksperimental Pengaruh Panjang Chord Sudu Terhadap Unjuk Kerja Turbin Pelton Untuk Sistem Pembangkit Listrik Tenaga Mikrohidro (PLTMH). "Sekripsi Pembangkit Listrik Tenaga Mikrohidro (PLTMH). Jurusan Teknik Mesin Universitas Lampung. Bandar lampung.

[5] A. Annasa Musaffa, 2010. "Pengaruh Kuat Medan Magnet dan Kecepatan Rotor terhadap Tegangan yang Dihasilkan Generator Arus Bolak-Balik Tugas Akhir, Fisika Fakultas Matematika dan Ilmu Pengetahuan Alam Universitas Surakarta, 